Article

\title{
Prioritization of Physical Assets for Maintenance and Production Sustainability
}

\author{
Orlando Durán ${ }^{1, *}$ and Paulo Andrés Durán ${ }^{2}$ \\ 1 Mechanical Engineering School, Pontificia Universidad Católica de Valparaíso, Quilpue CP 2430000, Chile \\ 2 Universidad Tecnológica de Chile INACAP, Valparaiso CP 2340000, Chile \\ * Correspondence: orlando.duran@pucv.cl
}

Received: 23 July 2019; Accepted: 5 August 2019; Published: 8 August 2019

\begin{abstract}
Maintenance is one of the main drivers for ensuring the sustainability of manufacturing in capital-intensive production systems. However, in many cases, as a result of budgetary constraints, it is necessary to select which machines will be subject to maintenance actions on the basis of a list of priorities. Traditionally, such prioritization decisions are made using techniques which, in general, do not consider the systemic impact of maintenance actions. This paper is focused at the definition of a novel graphical technique for physical assets prioritization. This technique is aimed at establishing maintenance priorities considering the impact on the overall throughput of the production system. Due to the fact that the proposed technique is based on the well-known Overall Equipment Effectiveness (OEE) index, its use is not only limited to measuring the effects of maintenance decisions and actions (availability), but also to operational implications (productivity and utilization). The results could be displayed graphically, which makes it particularly useful and manageable for different types of users. The methodology is illustrated though an example based on a comminution plant from the copper mine industry. It is evident how the proposed technique facilitates business-oriented and economic sustainability focused decisions.
\end{abstract}

Keywords: availability; maintenance sustainability; OEE; throughput

\section{Introduction}

Nowadays, it is well-established that a nation's wealth and economic growth depend on the prosperity of its industrial sector. As a consequence, manufacturing industry is constantly under strong pressure to increase its competitiveness. However, in the industrial sector, sustainability requirements are not yet considered as important as classic performance targets, such as productivity and costs [1]. However, the market is slowly moving towards the recognition of factors linked to sustainable development [2]. Thus, sustainability is becoming a preponderant factor for all organizations, whether public or private, for-profit or not-profit.

In addition, the growing demand from stakeholders for more comprehensive information on the operations and financial situation of companies has led some of them to include information on sustainability. This requires companies to extend their information beyond financial data. Gopalakrishnan et al. [3] summarized the main advantages and drawbacks of moving from a philosophy of strictly financial reporting to a philosophy of sustainability.

The current sustainable production model is mainly based on the concept of Triple Bottom Line (TBL) and its three dimensions: Economic, environmental, and social. According to References [4,5], the economic dimension has the largest priority, at the expense of the environmental and social dimensions. Winroth et al. [6] presented a literature review on Sustainability Indicators (SI) applied in industries and identified a total of 28 indicators. Of these indicators, 11 are related to the environmental dimension, 7 to the economic dimension, and 10 to the social dimension. On the other 
hand, Wan Mahmood et al. [7] provided a systematic review of the literature on the integration of performance measurement (PM) and sustainability reporting (SR) applying content analysis. The focus of this research was to determine how the performance measurement system (PMS) supports the development of an effective sustainability report. An important challenge in the assessment of sustainability is using a single sustainable index and how to measure it [8].

In industrial enterprises, economic sustainability tends to be understood or linked to the manufacturing sustainability. Indeed, according to the Organization for Economic Co-operation and Development (OECD) definition, sustainable manufacturing is about minimizing the various business risks inherent in any manufacturing operation while maximizing the new opportunities arising from the improvement of its processes and products [9]. Also, the OECD defined a cycle with seven steps for establishing requirements for sustainable manufacturing [10]. These steps were grouped into three main stages: Preparation, measurement, and improvement. The preparation stage initially involves the mapping and auditing of the impacts that companies generate on the environment and, subsequently, the definition of priorities through the correct selection of performance indicators. In the measurement stage, it is necessary to carry out the evaluation of the influence levels that the inputs and resources of the productive system generate to the environment. Finally, in the improvement stage, along with the evaluation of performance indicators, the improvement opportunities must be identified and selected. These opportunities should be implemented to close the cycle.

Thus, the practices most frequently implemented by manufacturing organizations are, for example, measuring financial key performance indicators (KPIs), monitoring and evaluating business objectives, and prioritizing investment in technology [11]. On the other hand, the scarcity of natural resources, together with climate change, have prompted manufacturing companies to intensively increase their concern and awareness of environmental impacts [12]. Thus, manufacturing companies have introduced so-called green practices in their operating strategies [13], improving their eco-efficiency. In general, the development of sustainable manufacturing practices, as well as their efficiency assessment systems, is observed at three levels: Products, processes, and systems. Recently, Sellitto [12] highlighted that green manufacturing practices not only refer to the interior of individual companies, but also extend throughout the logistics chain, integrating internal practices, such as green manufacturing and purchasing with external initiatives, like cooperation with suppliers, distributors, or customers, and reverse logistics.

More recently, Negri et al. [14] proposed a methodology for the integrated assessment of the sustainability of the life-cycle of a product-service system in order to support continuous improvement on the part of both the manufacturer and the user. In addition, they suggest a set of indicators for the three dimensions-economic, environmental and social-aligned with the concept of service unit, based on bibliographic evidence.

Next, the challenge arises of measuring the level of manufacturing sustainability and the contribution degree to the organization's sustainability. According to Garbie [15], the main challenge for manufacturing companies in terms of sustainability is the modelling and measurement of performance metrics that integrate the dimensions of sustainability. Garza-Reyes [16] proposed a repository of sustainability indicators, called the Sustainable Manufacturing Indicators Repository (SMIR), which envisages the integration and extension of 13 sets of popular sustainability indicators. Joung et al. [17] reviewed a set of indicators and provided a categorization of indicators that are quantifiable and clearly related to sustainable manufacturing.

Recently, Viveros et al. [18] proposed a sustainable manufacturing measurement infrastructure that allows indicators to be measured within the manufacturing environment and considers the possibility of aggregation at all levels of the organization.

In a study by Rachuri et al. [19], Overall Equipment Efficiency (OEE) is proposed as an affordable solution for measuring sustainability. According to Esa and Yusof [20], O.E.E. establishes a link between manufacturing activities and sustainability. Therefore, the use of OEE in manufacturing cannot be underestimated. According to Ibrahim et al. [21], the OEE has become a major concern for modern 
manufacturing technology systems. However, limited empirical knowledge is available to confirm the effect of such approach on business performance and, finally, on economic sustainability. To fill this gap, the study aimed to assess the relationship between Fit Manufacturing (Lean Manufacturing, Agile Manufacturing and Sustainability) and Business Performance through the mediation of the OEE.

Wan Mahmood et al. [7] carried out a literature review to establish the connection between the OEE and the sustainability of manufacturing. The author examined the three factors that contribute to the OEE: Availability, performance and quality, and the components of sustainable manufacturing, including environmental conservation, social efficiency, and economic improvement. Their conclusions can be used as an initial reference for manufacturers to consider the OEE to advance the goal of sustainable manufacturing.

Production levels are often compromised by failures during work, which can lead to economic losses for the company [22]. Such losses include breakdown loss, installation/adjustment loss, idle loss and minor shutdown loss, reduced speed loss, reduced yield loss, and reprocessing loss. These losses are intimately related to the maintenance and operations decisions. According to Franciosi et al. [23], the maintenance process is the one that must guarantee the availability, reliability, and safety of the equipment, playing a key role for sustainable productive operations. Similarly, operational decisions should aim to reduce idleness and detentions due to lack of product, operators, or adjustments, among other reasons. Zuashkiani et al. [24] mapped the dynamics of the OEE to improve asset management strategies using dynamic mapping of the maintenance function. These maps show, among other aspects of this dynamic, production pressure and maintenance performance, the effect of cost on the delay of long-term investments, and conflicts between maintenance and production. Based on these diagrams, we proposed a simplified one that summarizes the relationships between the main aspects of the OEE and its components (Figure 1).

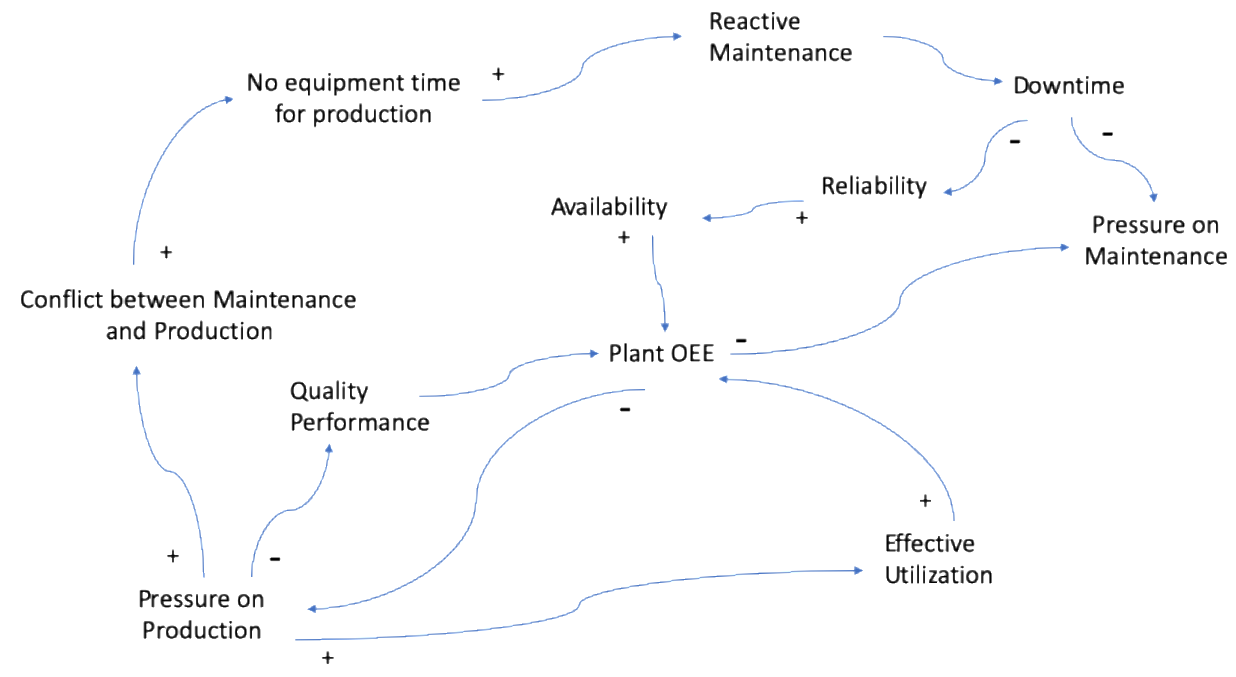

Figure 1. Causal Diagram: Impacts on production and maintenance.

Thus, in order to achieve sustainable development, strategic and continuous efforts involving the entire organization are required, where maintenance efforts play a leading role [25], mainly in capital asset-intensive organizations. According to [26], maintenance activity is, by nature, an important driver for action on the sustainability in production systems. Still, according to the same authors, maintenance plays a fundamental role in maintaining operational continuity through safety management, energy savings, plant and machinery breakdowns, and productivity, among others. The performance of maintenance must be measured to assess the level of achievement of business objectives toward sustainable development.

However, the way in which maintenance can integrate the sustainability goal and contribute to this goal is not clearly defined. According to [23], few studies addressing this issue are available in the 
current literature. Ref. [27] characterized industrial maintenance in a context of sustainability through a systematic review of the literature. Ref. [11] developed a sustainable maintenance performance assessment model for the cement industry. According to the authors, sustainability measurement is a process of continuous development and constant improvement of maintenance processes, increasing efficiency (operational excellence), the safety of operations, and the maintenance of technical objects and installations, with a focus on employees.

The relationships between the maintenance function and the OEE were mapped in a detailed work by [24]. Based on knowledge of systems dynamics and strategic management literature, feedback loops were designed to reinforce the maintenance function and its interactions with various elements of a company.

Pires et al. [27] proposed an approach to prioritize the drivers of sustainable maintenance by prioritizing the factors present in the TBL approach by connecting them to the OEE. According to Esa and Yusof [20], the affirmative of implementing the OEE is very important for the organization's sustainability management. Therefore, OEE management can be seen as a process of culture transformation through which existing elements of culture are modified, replaced, or reinforced with better elements.

Sari et al. [28] developed a framework for measuring sustainable maintenance performance. This framework identifies 15 measures at the corporate level, 20 measures at the tactical level, and 43 measures at the functional level. The economic dimension of sustainability is divided into three dimensions: Cost, quality, and productivity. In the quality dimension and at the corporate level, Overall Plant Effectiveness appears, while in the productivity dimension, mention is made of the efficiency of maintenance. Going deeper into the levels, aspects such as availability, mean time to repair and mean time between failures (MTTR and MTBF respectively) and OEE also appear.

Wan Mahmood et al. [7] also proposed a framework that relates each dimension of TBL to the OEE factors (system availability, equipment performance, production quality). From that, the attributes that best influence sustainability are grouped. More recently, [29] investigated maintenance prioritization decisions, as well as developing and validating maintenance decision support to increase productivity.

For Charaf and Ding [30], the OEE frees managers from short-term vision and provides the prospect of continuous improvement. Using the OEE, the performance of the equipment is evaluated, unmasking all machine performance losses and indicating possible corrective or preventive actions.

Ref. [2] demonstrated that a systematically used set of combined OEE and productivity measures can successfully drive production improvements. The work of Garza-Reyes et al. [31] investigated the relationship between OEE and process capability. On the same note, Shahidul et al. [32] emphasized that the underutilization of machinery capacity appears as a hidden factor without added value in the production process that does not contribute to raising the throughput of the production system. Two interesting works on application of the concept of OEE combined with environment issues are $[33,34]$.

In every production system, each machine or equipment contributes in different degrees to overall results and to its throughput. This situation can be represented by a function of a complex set of cause-effect interrelationships and synergies [24]. Therefore, it is necessary to be aware that not every piece of equipment contributes with the same intensity to the performance of the system considering its specific levels of availability, utilization, and productivity. Indeed, not only the availability (a maintenance KPI) of each piece of equipment will determine its importance, but a combination between this and the levels of effective capacity utilization and productivity of each of them is needed, taking into account the general taxonomy of the productive system. In the literature, there is no model or technique that allows the measurement of this impact, taking into account the different configurations of the productive system (series, parallel, and others).

This is why machine level metrics, as well as also other indices that take into account the contribution each machine makes to the performance of the entire system, are required. A series of global performance indices focused on determining bottlenecks and identifying hidden capabilities 
have been proposed [16,35]. Gólcher-Barguil et al. [36] presented an interesting research stream of the OEE which analyze the scope and calculations modifications of about 10 new developments. However, none of these indices are intended to determine the impact of maintenance actions have at the systemic level.

From the point of view of the systemic impact, it is necessary to establish a hierarchy of physical assets regarding the degree of influence or impact that each equipment provokes into efficiency of the overall performance (throughput) of the system.

Such prioritization efforts have to take into account the performance and the impact generated at the systemic level by an increase or reduction in their availability, utilization levels, and performance (i.e., OEE fluctuations). The model for maintenance management developed by [37] precisely includes the prioritization of assets as the second phase of his model. There are several approaches that can be used to prioritize assets looking for optimized asset management decisions. The most commonly used techniques for prioritizing physical assets are Pareto Diagrams, Jack Knife and Multicriteria Methods (MCDM), such as AHP and Delphi. It is also important to remember that criticality analysis is a fundamental phase of RCM and FMECA [38]. Regarding those techniques, the Risk Priority Number (RPN) is used as a multicriteria index of evaluation [37]. Kristjanpoller et al. [39] proposed a methodology called RAM-C, which reveals the effect of each equipment on the system that contains it, including situations where the logical configuration is not serially dependent. This methodology establishes a hierarchy among the assets of a productive system using as base the so-called impact factor of each one of them. For the calculation of this index, the availability and configuration of the equipment is taken into consideration, but not the effect that the loss of availability may generate in the production rates at system level. Recently, Pascual et al. [40] proposed a method for prioritizing equipment using a technique called System Efficiency Influence Diagram (SEID), which allows for the identification of equipment on a production line that generates the greatest impact on production rates in order to define appropriate maintenance policies. Later, Pascual et al. [41] applied the aforementioned methodology as an iterative optimization procedure based on the performance of the production system through concepts of constraint theory and bottleneck detection.

The hierarchy of assets requires a "comparison" between them. This comparison must necessarily be made from a higher level of analysis than that of the machine level, providing a systemic vision of the whole. Thus, there are two levels of analysis for the unavailability: (i) Machine level, (ii) systemic. In this sense, an equipment will be more critical if its unavailability leads to the unavailability of the system [42]. In many cases, local unavailability does not cause a severe impact on production at the system level. This should be reflected in maintenance planning and decisions. This is the case, for example, of an event of unavailability in a redundant equipment. It is this redundancy that prevents the unavailability of a piece of equipment from being transferred to the system in a certain degree of influence. Thus, it is necessary to distinguish equipment that present a lower criticality level from others with greater criticality, and consequently, create adjusted maintenance plans taking into account these differences.

Consequently, the present work raises the following hypothesis: "It is possible to define a prioritization list of equipment to plan maintenance actions according to the impact that the variation of the operational variables (availability, use, and productivity) of each individual equipment causes in the global throughput and in the generation of value for sustainable manufacturing".

The aim is to generate a technique that take into account these key aspects, which are directly related to the business objectives, the generation of value, and the maintenance of a sustainable productive system. In this paper, we try to make a contribution in this sense.

\section{Antecedents}

At the end of the 1980s, an Overall Equipment Efficiency (OEE) was created. The initial objective was "to measure the productivity of a piece of equipment in relation to its maximum capacity, which is assumed to be constant over a total period of time" [43]. However, this definition has been adapted 
according to the different applications according to the specificities of the systems and equipment in which they have been used. For example, Muthiah and Huang [35] proposed a new index based on the OEE in order to create an Overall Throughput Effectiveness (OTE) to allow the detection of bottlenecks in production systems. In this way, they established a new concept, called theoretical OEE. The main difference, according to the definition presented by Nakajima, lies in that capacity is no longer constant during the total period of time under analysis.

On the other hand, Paraszczak [44] published an article related to the evaluation of effectiveness in mining equipment. Based on the general definition of OEE given by Nakajima [43] and based on Campbell and Jardine [45], the work structured the new definition of the OEE on the differences that exist between mining equipment and manufacturing industry equipment.

The OEE, as mentioned above, is the product of availability efficiency $\left(A_{\text {eff }}\right)$, which takes into account the effects of breakdowns and repairs; productive performance $\left(P_{\text {eff }}\right)$, i.e., loss of productivity due to loss of rhythm, stops, and waiting; and quality efficiency ( $\left.Q_{\text {eff }}\right)$, and subtracts losses due to defects and rework. Nakajima [43] defines this index as conventional OEE (Equation (1)):

$$
O E E=A_{e f f} \times P_{e f f} \times Q_{e f f}
$$

As mentioned above, Paraszczak (2005) proposed a new definition of the conventional OEE and redefines the $O E E$ with Equation (2):

$$
\text { OEE }=\text { Availability } \times \text { Utilization Rate } \times \text { Production (or Process) efficiency }
$$

where:

Availability is:

$$
\mathrm{A}=\left(\frac{\text { Uptime }}{\text { Nominal Time }}\right) \times 100 \%
$$

Effective Utilization is:

$$
\mathrm{U}=\left(\frac{\text { Operating Time }}{\text { UptTime }}\right) \times 100 \%
$$

Production efficiency is:

$$
\mathrm{A}=\left(\frac{\text { Operating Time at Nominal speed }}{\text { Operating Time }}\right) \times 100 \%
$$

Figure 2 shows the graphical demonstration of the aforementioned relationships among the three OEE elements.

Total or Nominal Time (h)

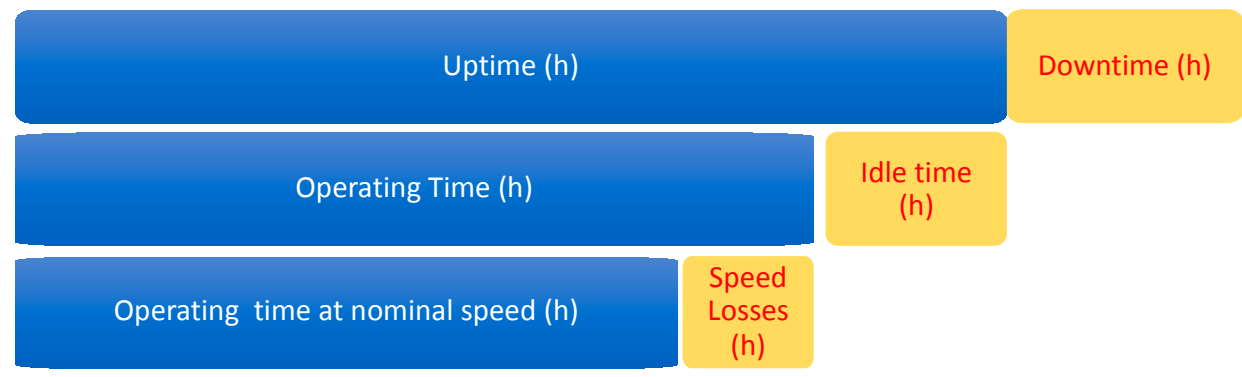

Figure 2. Overall Equipment Efficiency (OEE) elements. 


\section{Overall Throughput Effectiveness (OTE)}

The Overall Throughput Effectiveness (OTE), an index with systemic vision, was proposed by [35] in order to measure the productive performance of production lines taking into account the taxonomy of the equipment present in the system. This index takes into account the OEE of each piece of equipment and makes it possible to carry out factory level diagnostics, detect bottlenecks, and identify hidden capacities.

OTE is developed on the basis of comparing the actual throughput with respect to the maximum throughput achievable by the system [35]. To define the O.T.E. in a simplified way, and paraphrasing the OEE definition, we present the two following equations (Equations (6) and (7)):

$$
O E E=\frac{\text { Actual throughput (units) from equipment in total time }}{\text { Theoretical throughput (units) from equipment in total time }}
$$

By scaling the scope to the factory level, the overall throughput effectiveness can be defined as it is shown in Equation (7):

$$
\text { OTE }=\frac{\text { Actual throughput (units) from factory in total time }}{\text { Theoretical throughput (units) from factory in total time }}
$$

By extending the scope to the system level, this is accomplished on the basis of various structures, within which the most recurrent are the following configurations or taxonomies: Series, parallel, assembly, and expansion (Figure 3). The Equations (8)-(11) show the specific equations developed for each one of the possible subsystem configurations [35]:

$$
\begin{gathered}
\text { Series OTE }=\frac{\min \left\{\min _{i=1,2, \ldots n-1}\left[\operatorname{OEE}_{(i)} R_{t h(i)} \prod_{j=i+1}^{n} Q_{e f f(j)}\right], O E E_{(n)} R_{t h(n)}\right\}}{\min _{i=1,2, \ldots, n}\left\{R_{t h(i)}\right\}} \\
\text { Parallel OTE }=\frac{\sum_{i=1}^{n}\left(O E E_{(i)} R_{t h(i)}\right)}{\sum_{i=1}^{n} R_{t h(i)}} \\
\text { Exsembly OTE }=\frac{\min \left\{\min _{i=1,2, \ldots n-1}\left[O E E_{(i)}\left(\frac{R_{t h(i)}}{k_{A(i)}}\right) Q_{e f f(a)}\right], R_{t h(a)} O E E_{(a)}\right\}}{\min \left\{\min _{i=1,2, \ldots n-1}\left[\left(\frac{R_{t h(i)}}{k_{A(i)}}\right) Q_{e f f(a)}\right], R_{t h(a)}\right\}} \\
\sum_{i=1}^{n} \min \left(R_{t h(e)} O E E_{(e)} k_{E(i)} Q_{e f f(i)}, R_{t h(i)} O E E_{(a)}\right) \\
\sum_{i=1}^{n} \min \left\{R_{t h(e)} k_{E(i)}, R_{t h(i)}\right\}
\end{gathered}
$$

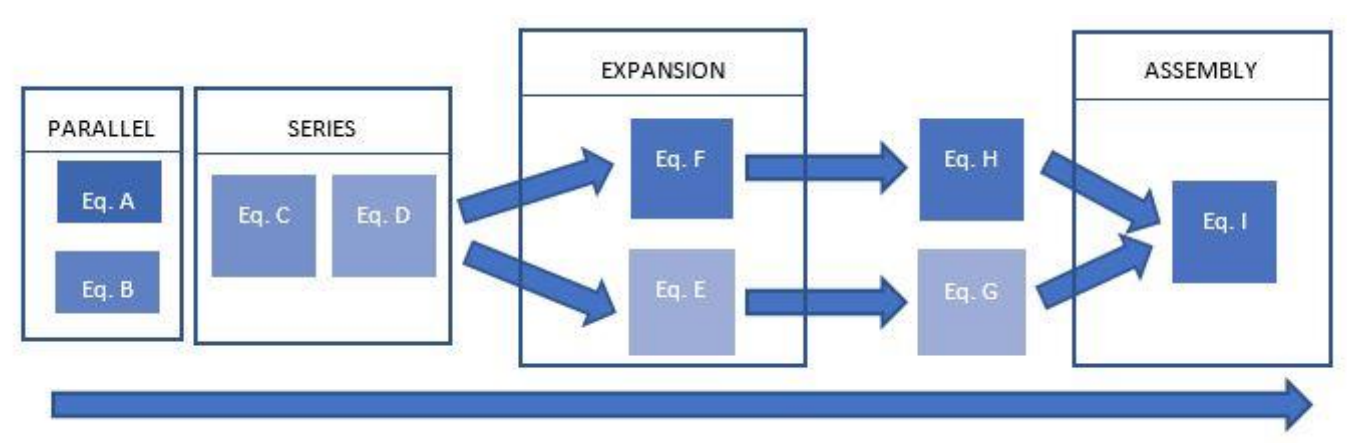

Figure 3. Arrangement of the different subsystems: Series, parallel, assembly, and expansion.

In general, modelling assumes that the equipment processes different products. Let $Q_{\text {eff }(i j)}$ and $R_{t h(i j)}$ be the quality efficiency and the theoretical processing rate of the equipment $i$ when processing 
product $j(j=1,2, \ldots, n)$, respectively. Let $X_{(i j)}$ be the product mix percentage of product $j$ at the equipment $i\left(Q_{\text {eff (i) }}\right.$ and $R_{t h(i)}$ for multiple products, which can be calculated as follows:

$$
\begin{aligned}
Q_{e f f(i)} & =\sum_{j=1}^{n}\left(X_{(i j)} x Q_{e f f(i j)}\right) \\
R_{t h(i)} & =\sum_{j=1}^{n}\left(X_{(i j)} x R_{t h(i j)}\right)
\end{aligned}
$$

\section{Methodology}

Regarding the OTE indicator, it is possible to carry out a sensitivity study with respect to variations in the availability and utilization of each equipment within a production system. That is, the systemic impact of the percentage increase or decrease in the availability and/or in the utilization of each piece of equipment. From this sensitivity analysis, it is possible to obtain a ranking of the equipment according to its impact on overall performance either from the availability or the utilization point of view. As the objective of this model is to prioritize maintenance actions toward the equipment that can "take better advantage" of the improvement in its availability, another aspect must be taken into account: Its effective utilization. In other words, what is the percentage of the available time which is being used? One can easily see that the higher the utilization, the better use is being made of the available time. A piece of equipment that is in this situation can be considered as constrained by the availability (therefore, by maintenance performance). On the other hand, the equipment, which is underutilized despite of having high levels of availability, is constrained by operational issues, such as an unprepared workplace, operator absence, or other kind of idleness.

Finally, as previously mentioned, it is not equally worthwhile to increase performance of any equipment, but it is strongly recommended to increase the equipment's performance that generates the greatest impact at the system level and a throughput increment. Therefore, priority should be given to maintenance actions that will increase the availability of equipment that meets the following requisites: Low maintenance performance, high level of utilization, and a high impact on overall efficiency. The equipment is represented by point A in Figure 4. Another equipment may have high availability, but low levels of utilization and lower impact factors (point B in Figure 4). That is, from the maintenance point of view, such equipment must be considered with a lower level of priority, because an improvement in its availability will not directly imply an increase if the overall throughput.

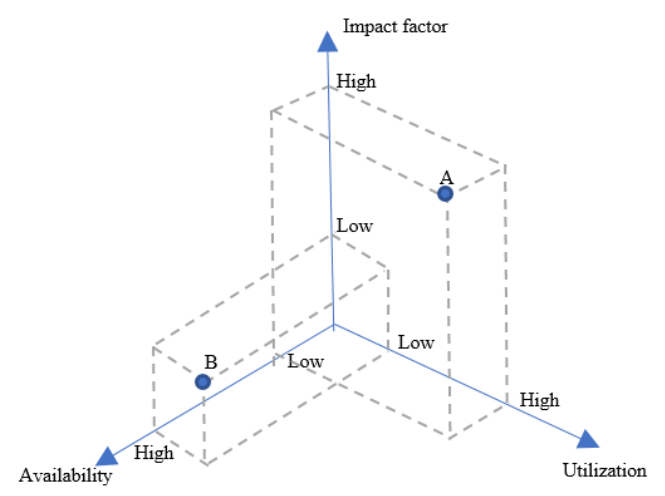

Figure 4. Scatter diagram relating three main variables of the proposed technique.

Therefore, three perspectives can be extracted from this approach. Figure 5 shows perspective I. In perspective I, the relationships between machine availability and impact factor can be observed. From this perspective, we can identify the physical assets which present low levels of availability in conjunction with high impact factor (equipment A). Those assets need to increase their maintenance 
performance because such increment will impact significantly in the overall throughput. Figure 6 depicts the relationship between the equipment utilizations and the impact factor (perspective II). Similar to perspective I, here it is possible to identify the equipment which present low levels of utilization and high impact factor (equipment B). This is the case of physical assets which are stressed to increase their utilization because such increment will impact directly in the OTE.

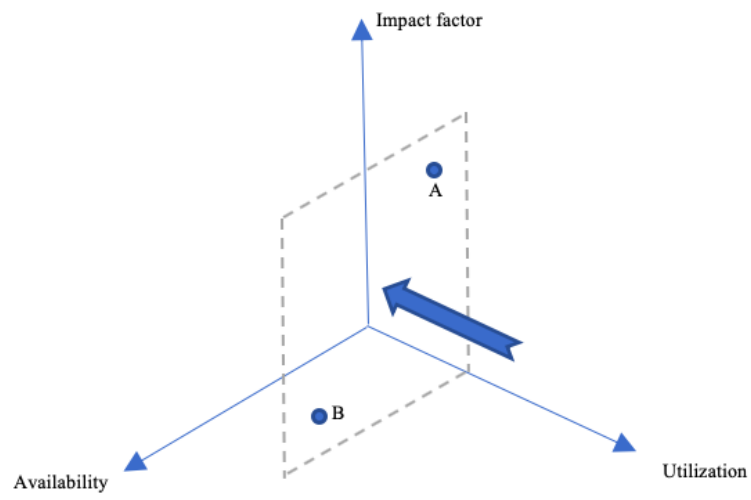

Figure 5. Perspective I: Availability vs. Impact factor.

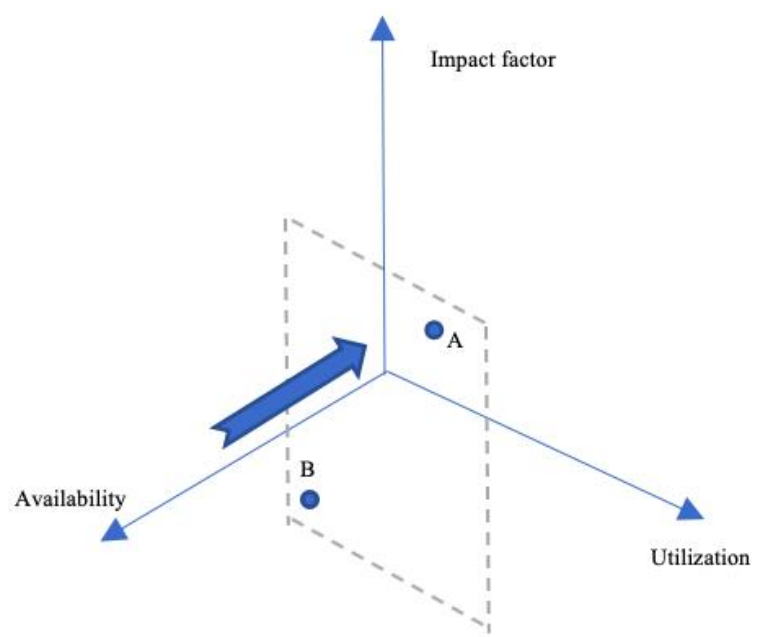

Figure 6. Perspective II: Utilization vs. Impact factor.

Through the use of both perspectives, the equipment with the lowest availability and utilization, but with great systemic impact factor, have to be recognized as priorities from the point of view of maintenance and operations.

In the third perspective (Figure 7), the relationship between availability and utilization can be analyzed. This perspective is vital for determining what assets are presenting low levels of availability in combination with higher levels of utilization (equipment A). In such category, the equipment which need to increase their availability levels are positioned. This is true under the assumption that any increment in availability can be translated into additional utilization with the consequent increment in the overall throughput (the highest possible). 


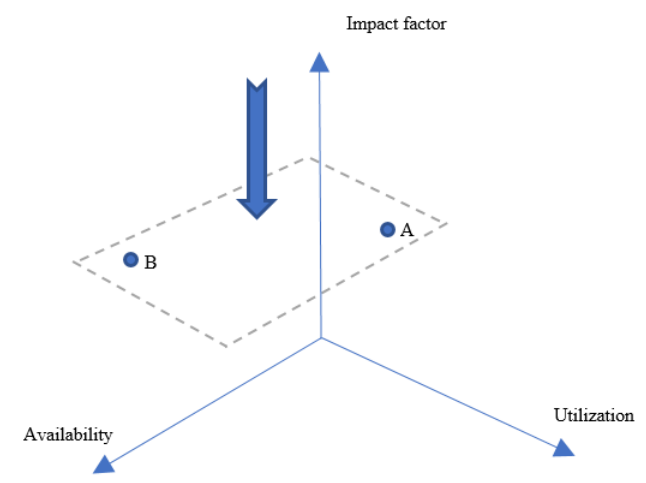

Figure 7. Third perspective: Availability vs. Utilization.

In order to estimate the impact factor, a sensitivity study of the OTE to variations in the availability values of each piece of equipment must be carried out. This analysis is carried out by varying the availability value of a piece of equipment, ceteris paribus, and measuring the variation of the OTE. Once the effect of the variations in the availability of each of the equipment has been measured, the so-called impact factor (IF) is calculated, which will allow each equipment to be ranked according to this value:

$$
I F=\frac{\left(\mathrm{OTE}_{\text {max }}^{j}-\mathrm{OTE}_{\text {min }}^{j}\right)}{\mathrm{OTE}_{\text {max }}^{j}}
$$

where $\mathrm{OTE}_{\text {max }}^{j}$ and $\mathrm{OTE}_{\text {min }}^{j}$ are the values of the OTE obtained by varying between the ranges of variation of the available equipment $j$. The greater the value of $I F$, the greater the systemic impact caused by the variability of the availability of such equipment.

\section{Case Study}

As a means of illustrating the use of the proposed model, a simulation exercise is presented to calculate the values of the proposed metric and to define the prioritization list among a series of physical assets. As a basis, we used data obtained from a crushing plant used in a copper mining operation located in the Chilean Andes.

In this plant, the first size reduction of the ore from the mine is made, where the ore is sent to the transfer hopper. The plant has a nominal capacity of 4200 [TPH]. The figure shows the flow diagram of the plant and the configuration of the main equipment that make up the plant.

From the configuration point of view, it is initially considered that the two feeders (1 and 2) are working in parallel forming a work station, which is in series with the rest of the equipment, as shown in Figure 8. Figure 9 shows the availabilities for each of the equipment for seven months during which the analysis lasts, and Figure 10 shows the utilization of the aforementioned equipment for the same seven months under analysis. Finally, the performance has been measured as the actual production level with respect to the nominal production capacity as shown in Table 1 . The values are identical for all the equipment, as they are calculated from the product that comes out at the end of the line in each period. 


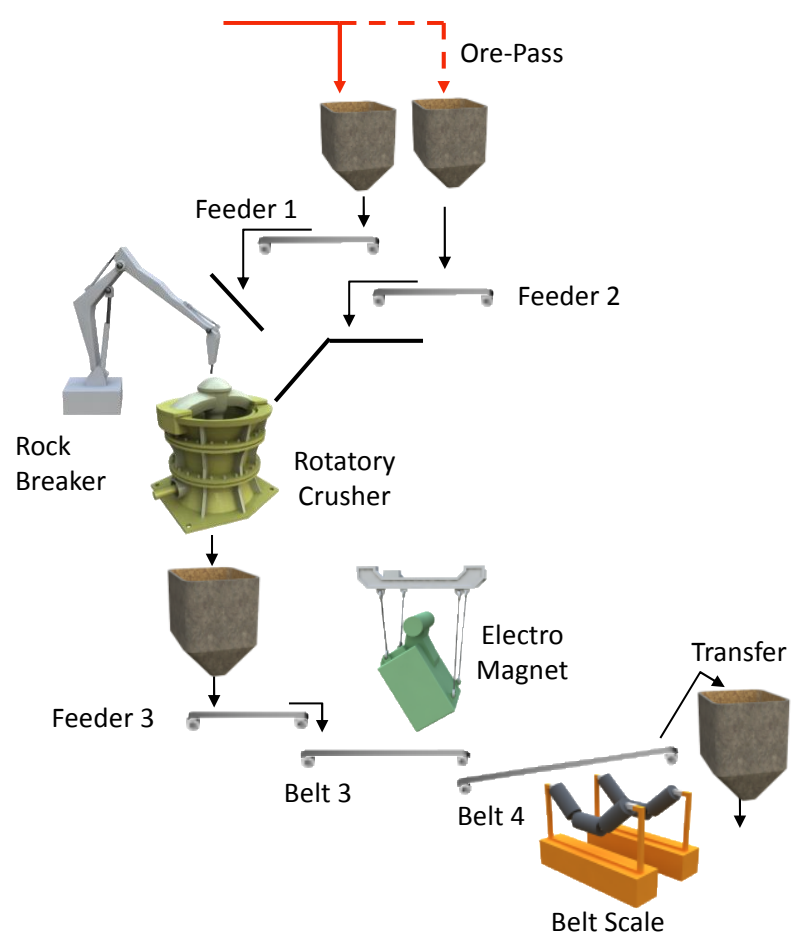

Figure 8. Comminution Plant flowsheet.

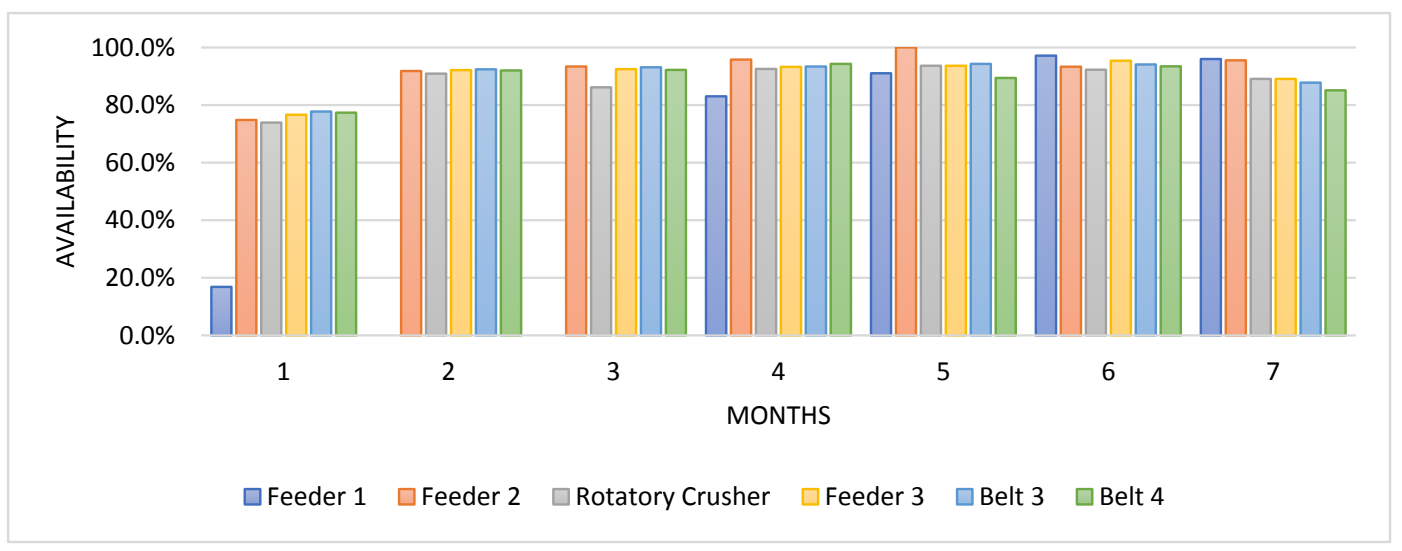

Figure 9. Availabilities.

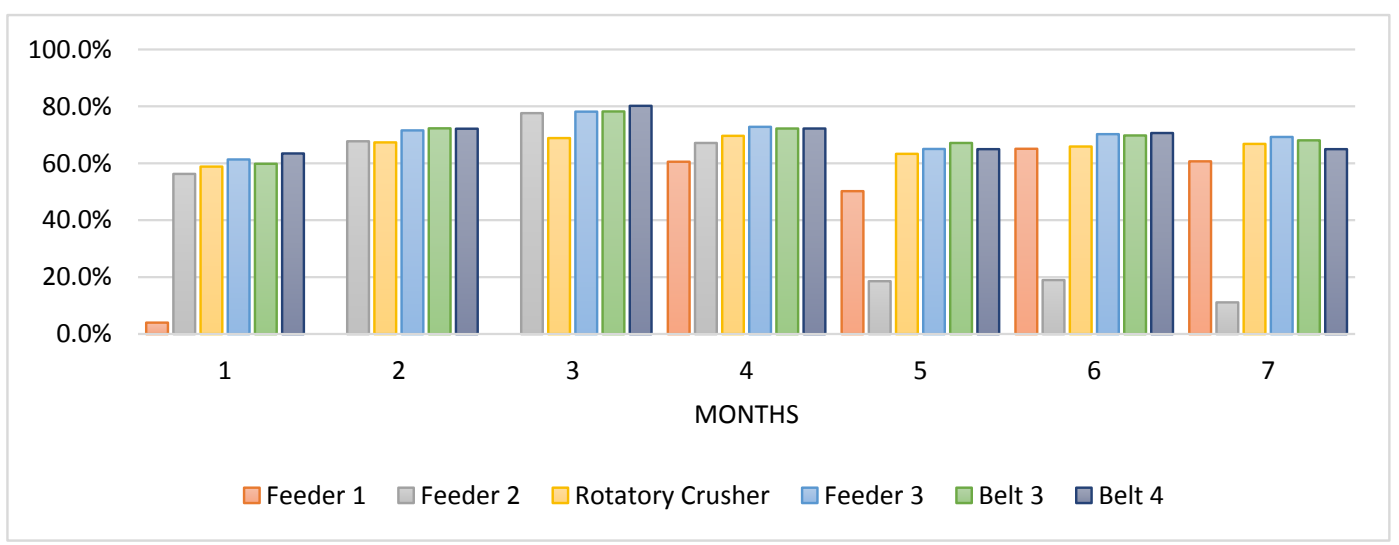

Figure 10. Utilization rates. 
Table 1. Monthly Performances for the line under analysis.

\begin{tabular}{ccccccc}
\hline $\mathbf{1}$ & $\mathbf{2}$ & $\mathbf{3}$ & $\mathbf{4}$ & $\mathbf{5}$ & $\mathbf{6}$ & $\mathbf{7}$ \\
\hline $82.1 \%$ & $87.3 \%$ & $86.1 \%$ & $87.1 \%$ & $89.7 \%$ & $85.6 \%$ & $87.2 \%$ \\
\hline
\end{tabular}

Table 2 shows the calculated values of the OTE for eight months under analysis.

Table 2. OTE for eight months under analysis.

\begin{tabular}{cccccccc}
\hline Months & $\mathbf{1}$ & $\mathbf{2}$ & $\mathbf{3}$ & $\mathbf{4}$ & $\mathbf{5}$ & $\mathbf{6}$ & $\mathbf{7}$ \\
\hline OTE & $22.50 \%$ & $34.40 \%$ & $36.70 \%$ & $40.15 \%$ & $39.86 \%$ & $35.29 \%$ & $36.29 \%$ \\
\hline
\end{tabular}

After that, the values of the impact factor were calculated (using Equation (14)). These values are shown in Table 3 beside the average values of the availability and utilization of each equipment.

Table 3. Computed values.

\begin{tabular}{cccc}
\hline Equipment & Availability & Utilization & Impact Factor \\
\hline Feeder 1 & $54.87 \%$ & $56.41 \%$ & $31.80 \%$ \\
\hline Feeder 2 & $92.09 \%$ & $50.40 \%$ & $52.80 \%$ \\
\hline Rotatory Crusher & $88.35 \%$ & $74.71 \%$ & $88.80 \%$ \\
\hline Feeder 3 & $90.36 \%$ & $77.34 \%$ & $86.40 \%$ \\
\hline Belt 3 & $90.41 \%$ & $77.06 \%$ & $84.40 \%$ \\
\hline Belt 4 & $89.10 \%$ & $78.40 \%$ & $81.60 \%$ \\
\hline
\end{tabular}

\section{Results and Discussion}

Figure 11 shows the scatter plot with the results of the case considering four of the main critical equipment. Note that the equipment with the highest impact factor, the rotary crusher (rc), has a utilization of $74.71 \%$ and an availability of $88.35 \%$. This means that not all availability is being used. On the other hand, feeder 3 (f3) has an impact factor of $86.40 \%$, utilization of $77.34 \%$, and availability of $90.36 \%$. These two equipment must be considered as priority, since they present two characteristics that are significant for maintenance actions and contribute significantly to the throughput of the system. That is, high impact factor, as well as effective utilization close to the available time generated by the maintenance (uptime in Figure 2). In short, maintenance efforts should focus on this two equipment, since the increases in availability and utilization of the rotary crusher will generate the greatest impact on the overall throughput. In the case of feeder 3 (f3), which has the second highest impact factor of all the equipment, its effective utilization levels are relatively high. This "forces" the maintenance to make an effort to increase the available time so that it can be used positively, strongly impacting the overall throughput. 


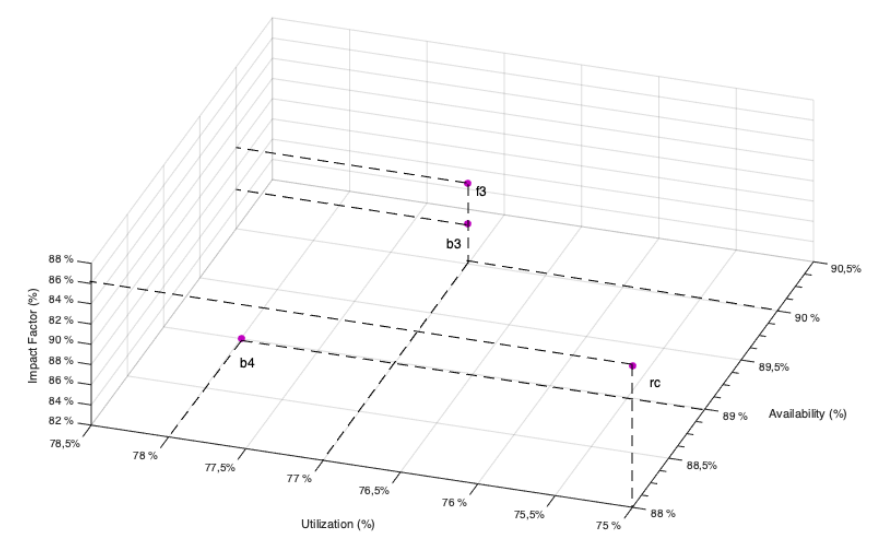

Figure 11. Scatter diagram for four of the main critical equipment.

\section{Trend Analysis}

An additional benefit of the proposed technique is that they provide a useful means of visualizing changing trends in maintenance priorities. Table 4 shows the evolution of behavior analyzed over a period of three consecutive years. Figure 12 shows the behavior over time of these indicators. The arrows indicate the migrations of these indicators throughout the comparison period.

By observing Figure 12, the following facts can be observed. In the case of the feeder 2, during the three years of analysis, there was a significant drop in the levels of utilization. This would undermine the added value that the maintenance function is expected to create, as $50 \%$ of the available capacity would not be being used. Also, in the case of the feeder 1 and the rotary crusher, the utilization increased, adding greater pressure to the maintenance to contribute with higher values of availability (or at least, maintain it), so as to increase or not lose performance at the system level.

However, the levels of sensitivity of the OTE to variations in the utilization in both cases are significantly different. In the case of the feeder, the sensitivity is lower than in the case of the rotary crusher. In other words, the overall performance will vary to a greater degree when the availability of the rotary crusher undergoes variations in its availability. In other words, there will be more pressure on the maintenance function to increase the availability performance of such equipment in order to improve the overall throughput levels, owing to the levels of equipment utilization being near its availability.

Table 4. Trends in utilization and impact factor over three months of analysis.

\begin{tabular}{cccc}
\hline & Years & Utilization & Impact Factor \\
\hline \multirow{2}{*}{ Feeder 3 } & 1 & $90 \%$ & $84 \%$ \\
\cline { 2 - 4 } & 3 & $50 \%$ & $90 \%$ \\
\hline \multirow{2}{*}{ Feeder 1 } & 1 & $40 \%$ & $45 \%$ \\
\cline { 2 - 4 } & 3 & $90 \%$ & $39 \%$ \\
\hline \multirow{2}{*}{ Rotary Crusher } & 1 & $70 \%$ & $90 \%$ \\
\cline { 2 - 4 } & 3 & $90 \%$ & $88 \%$ \\
\hline
\end{tabular}




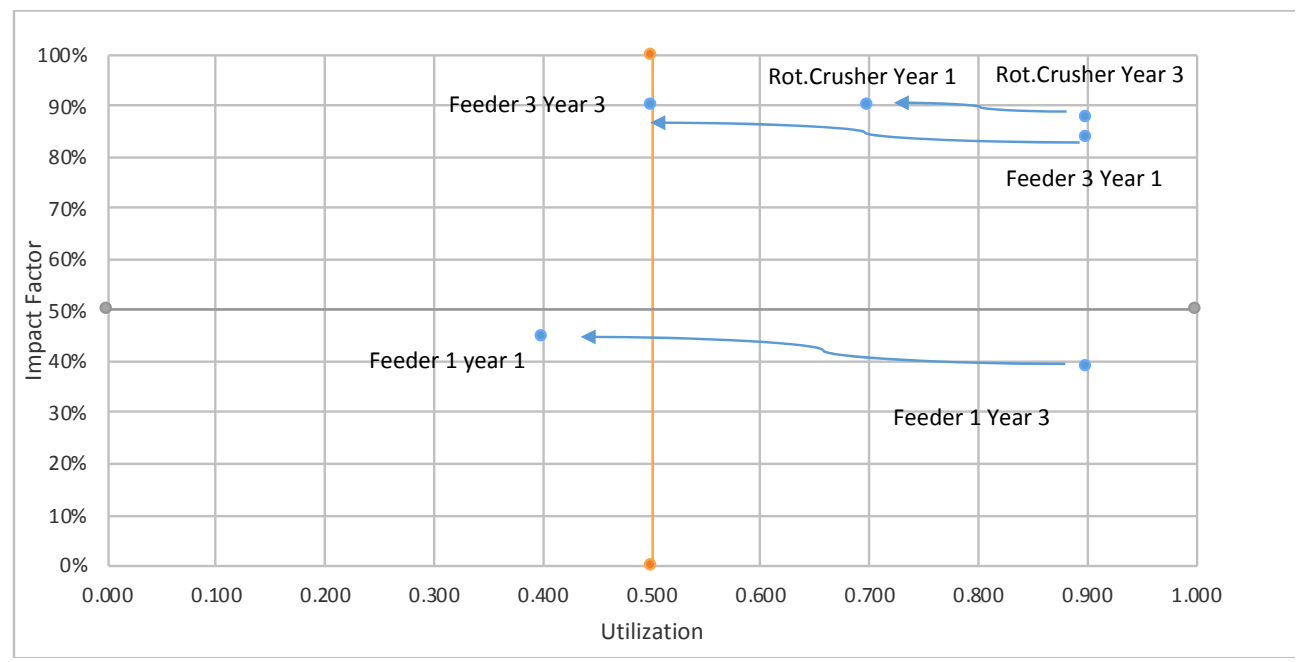

Figure 12. Dispersion diagram for trend analysis of three most influent equipment.

Trend analysis using the proposed techniques provides a useful visual means for analyzing and controlling maintenance priorities from the overall throughput point of view. Through this type of analysis, it is possible to assist the definition of maintenance budgets and devote more attention to that equipment that can effectively contribute to increase the productive performance of the system, and finally, to the manufacturing sustainability. Likewise, with the appropriate maintenance attention it will be possible to avoid or reduce performance degradation due to a loss in the availability of such equipment.

\section{Conclusions}

This paper proposes a technique to prioritize maintenance actions on a set of equipment that make up a production system. This technique makes it possible to identify the points where a greater impact on the overall throughput can be caused by increasing the availability and utilization rates. The impact is measured through a sensitivity index, called impact factor, between the variation of the availability in each equipment and the overall throughput effectiveness. This sensitivity analysis takes into account the different configurations of the equipment (series, parallel, fragmentation, etc.). With this technique, the resources allocated to maintenance will be used more effectively to cause increases in production times, thus contributing to the production sustainability.

Additionally, the proposed technique allows for trend analysis. The utilization and availability performances on two different dates are compared, and by doing so, we were able to analyze the effect of decisions made in time and their effects in priorities.

The application possibilities of the proposed technique range from the strategic to the operational level, as it is quite general and easy to apply and utilize.

The proposed technique overcomes traditional prioritization techniques' disadvantages by adding a focused perspective of the impact of prioritization decisions on the overall throughput. The diagram proposed in this article considers additional information on the taxonomy of the production system. The effects of variations in availability and use are observed and are useful to define maintenance interventions. Unlike other more generic decision support techniques, it is easy to understand and use, as it is also based on standard KPIs and commonly present in any computerized maintenance management system.

The parameters' variability and uncertainty aspects constitute an interesting element to consider and can be addressed in the next steps of this research. In fact, the standard deviation of the availabilities, performances, and utilizations observed over time could be considered as a measure of risk associated with the priorities defined using the proposed technique. 
Another perspective that will be addressed in the future is the use of fuzzy logic as a way of incorporating certain levels of uncertainty into the technique.

Author Contributions: O.D. designed the research, defined the model and performed the result analysis and P.A.D. contributed to the writing and editing of the manuscript.

Funding: This research received no external funding.

Conflicts of Interest: The authors declare no conflict of interest.

\section{References}

1. Engert, S.; Baumgartner, R.J. Corporate sustainability strategy-Bridging the gap between formulation and implementation. J. Clean. Prod. 2016, 113, 822-834. [CrossRef]

2. Andersson, C.; Bellgran, M. On the complexity of using performance measures: Enhancing sustained production improvement capability by combining OEE and productivity. J. Manuf. Syst. 2015, 35, 144-154. [CrossRef]

3. Gopalakrishnan, M.; Skoogh, A.; Laroque, C. Simulation-based planning of maintenance activities by a shifting priority method. Proc. Winter Simul. Conf. 2015, 2015, 2168-2179.

4. Chiang, Y.H.; Zhou, L.; Li, J.; Lam, P.T.I.; Wong, K.W. Achieving Sustainable Building Maintenance through Optimizing Life-Cycle Carbon, Cost, and Labor: Case in Hong Kong. J. Constr. Eng. Manag. 2014, 140. [CrossRef]

5. Ye, X.; Xia, X.; Zhang, L.; Zhu, B. Optimal maintenance planning for sustainable energy efficiency lighting retrofit projects by a control system approach. Control Eng. Pract. 2015, 37, 1-10. [CrossRef]

6. Winroth, M.; Almström, P.; Andersson, C. Sustainable Indicators at Factory Level—A Framework for Practical Assessment. In Proceedings of the IIE Annual Conference 2012, Orlando, FL, USA, 19-23 May 2012; Volume 21, pp. 1-14.

7. Wan Mahmood, W.H.; Abdullah, I.; Md Fauadi, M.H.F. Translating OEE Measure into Manufacturing Sustainability. Appl. Mech. Mater. 2015, 761, 555-559. [CrossRef]

8. Garbie, I.H. Sustainable development index on macro-level in industrial estates and specialised sectors. Int. J. Ind. Syst. Eng. 2016, 24, 384-421.

9. Yazdi, P.G.; Azizi, A.; Hashemipour, M. An empirical investigation of the relationship between overall equipment efficiency (OEE) and manufacturing sustainability in industry 4.0 with time study approach. Sustainability 2018, 10, 3031. [CrossRef]

10. OECD. OECD Sustainable Manufacturing Toolkit. Available online: www.oecd.org/innovation/green/toolkit/ (accessed on 5 August 2019).

11. Jasiulewicz-Kaczmarek, M. Identification of maintenance factors influencing the development of sustainable production processes-A pilot study. IOP Conf. Ser. Mater. Sci. Eng. 2018, 400. [CrossRef]

12. Sellitto, M.A. Assessment of the effectiveness of green practices in the management of two supply chains. Bus. Process Manag. J. 2018, 24, 23-48. [CrossRef]

13. Walker, H.; Di Sisto, L.; McBain, D. Drivers and barriers to environmental supply chain management practices: Lessons from the public and private sectors. J. Purch. Supply Manag. 2008, 14, 69-85. [CrossRef]

14. Negri, E.; Holgado, M.; Wagner, D.; Grefrath, C.; Macchi, M.; Gudergan, G. Continuous improvement planning through sustainability assessment of product-service systems. Int. J. Product. Qual. Manag. 2016, 18, 168. [CrossRef]

15. Garbie, I.H. Integrating sustainability assessments in manufacturing enterprises: A framework approach. Int. J. Ind. Syst. Eng. 2015, 20, 343-368. [CrossRef]

16. Garza-Reyes, J.A. From measuring overall equipment effectiveness (OEE) to overall resource effectiveness (ORE). J. Qual. Maint. Eng. 2015, 21, 506-527. [CrossRef]

17. Joung, C.B.; Carrell, J.; Sarkar, P.; Feng, S.C. Categorization of indicators for sustainable manufacturing. Ecol. Indic. 2013, 24, 148-157. [CrossRef]

18. Viveros Gunckel, P.; Kristjanpoller, F.; López-Campos, M.; Crespo Márquez, A.; Pascual, R. Graphical analysis for overall effectiveness management: A graphical method to support operation and maintenance performance assessment. Qual. Reliab. Eng. Int. 2018, 34, 1615-1632. [CrossRef] 
19. Rachuri, S.; Sriram, R.D.; Narayanan, A.; Sarkar, P.; Lee, J.H.; Lyons, K.W.; Kemmerer, S.J. Sustainable Manufacturing: Metrics, Standards, and Infrastructure-Workshop summary. In Proceedings of the 2010 IEEE International Conference on Automation Science and Engineering, Toronto, ON, Canada, 21-24 August 2010.

20. Esa, F.; Yusof, Y. Implementing overall equipment effectiveness (OEE) and sustainable competitive advantage: A case study of hicom diecastings SDN. BHD. (HDSB). ARPN J. Eng. Appl. Sci. 2016, 11, 199-203.

21. Ibrahim, R.; Jamal, N.M.; Esmaeel, R.I.; Zakuan, N.; Mohd, N. ScienceDirect ScienceDirect effectiveness effectiveness $\mathrm{b}$ in Industry 4.0: C Trade-off Costing models for capacity optimization between used capacity and operational efficiency of business performance from the perspective manufacturing strategies: Fit. Procedia Manuf. 2018, 22, 998-1006.

22. Mansur, A.; Rayendra, R.; Mastur, M. Performance Acceleration on Production Machines Using the Overall Equipment Effectiveness (OEE) Approach. IOP Conf. Ser. Mater. Sci. Eng. 2016, 105, 1-7. [CrossRef]

23. Franciosi, C.; Iung, B.; Miranda, S.; Riemma, S. Maintenance for Sustainability in the Industry 4.0 context: A Scoping Literature Review. IFAC-PapersOnLine 2018, 51, 903-908. [CrossRef]

24. Zuashkiani, A.; Rahmandad, H.; Jardine, A.K.S. Mapping the dynamics of overall equipment effectiveness to enhance asset management practices. J. Qual. Maint. Eng. 2011, 17, 74-92. [CrossRef]

25. Parida, A.; Galar, D. Achieving sustainable development through maintenance excellence. J. Appl. Eng. Sci. 2012, 10, 79-84.

26. Sénéchal, O. ScienceDirect IFAC nomenclatures Performance indicators decision making in sustainable conditions based maintenance Performance indicators nomenclatures for decision making in sustainable Performance indicators nomenclatures for decision making in sustain. IFAC PapersOnLine 2018, 51, 1137-1142. [CrossRef]

27. Pires, S.P.; Sénéchal, O.; Loures, E.F.R.; Jimenez, J.F. An approach to the prioritization of sustainable maintenance drivers in the TBL framework. IFAC PapersOnLine 2016, 49, 150-155. [CrossRef]

28. Sari, E.; Shaharoun, A.M.; Ma'aram, A.; Mohd Yazid, A. Sustainable maintenance performance measures: A pilot survey in Malaysian automotive companies. Procedia CIRP 2015, 26, 443-448. [CrossRef]

29. Gopalakrishnan, M. Data-Driven Decision Support for Maintenance Prioritisation Connecting Maintenance to Productivity; Department of Industrial and Materials Science, Chalmers University of Technology: Göteborg, Sweden, 2018.

30. Charaf, K.; Ding, H. Is Overall Equipment Effectiveness (OEE) Universally Applicable? The Case of Saint-Gobain. Int. J. Econ. Financ. 2015, 7, 241-252. [CrossRef]

31. Garza-Reyes, J.A.; Eldridge, S.; Barber, K.D.; Soriano-Meier, H. Overall equipment effectiveness (OEE) and process capability (PC) measures: A relationship analysis. Int. J. Qual. Reliab. Manag. 2010, 27, 48-62. [CrossRef]

32. Shahidul, M.I.; Osman, M.S.; Syed Shahzali, S.T.; Yassin, A.; Ting, C.H.; Hishamuddin, A.H.; Azrin, M.S.; Adzlan, A.F.K. Measuring Production Capacity Utilization and Its Impact on Manufacturing Performance and Environment. Energy Environ. 2013, 7-12. [CrossRef]

33. Domingo, R.; Aguado, S. Overall environmental equipment effectiveness as a metric of a lean and green manufacturing system. Sustainability 2015, 7, 9031-9047. [CrossRef]

34. Durán, O.; Capaldo, A.; Duran Acevedo, P. Sustainable overall throughputability effectiveness (S.O.T.E.) as a metric for production systems. Sustainability 2018, 10, 362.

35. Muthiah, K.M.N.; Huang, S.H. Overall throughput effectiveness (OTE) metric for factory-level performance monitoring and bottleneck detection. Int. J. Prod. Res. 2007, 45, 4753-4769. [CrossRef]

36. Gólcher-Barguil, L.A.; Nadeem, S.P.; Garza-Reyes, J.A. Measuring operational excellence: An operational excellence profitability (OEP) approach. Prod. Plan. Control 2019, 30, 682-698. [CrossRef]

37. Parra, C.; Crespo, A.; Kristjanpoller, F.; Viveros, P. Stochastic model of reliability for use in the evaluation of the economic impact of a failure using life cycle cost analysis. Case studies on the rail freight and oil industries. Proc. Inst. Mech. Eng. Part O J. Risk Reliab. 2012, 226, 392-405. [CrossRef]

38. Gasca, M.C.; Camargo, L.L.; Medina, B. Sistema para Evaluar la Confiabilidad de Equipos Críticos en el Sector Industrial. Inf. Tecnol. 2017, 28, 111-124. [CrossRef]

39. Kristjanpoller, F.; Viveros, P.; Crespo, A.; Grubessich, T.; Stegmaier, R. RAM-C: A novel methodology for evaluating the impact and the criticality of assets over systems with complex logical configurations. In Proceedings of the Safety and Reliability of Complex Engineered Systems, Zurich, Switzerland, 7-10 September 2015. 
40. Pascual, R.; Godoy, D.; Louit, D.M. Throughput centered prioritization of machines in transfer lines. Reliab. Eng. Syst. Saf. 2011, 96, 1396-1401. [CrossRef]

41. Pascual, R.; Madariaga, R.; Santelices, G.; Godoy, D.; Droguett, E.L. A structured methodology to optimise throughput of production lines. Int. J. Min. Reclam. Environ. 2016, 30, 25-36. [CrossRef]

42. Javier, S.P.; Márquez, A.C.; Rosique, A.S. Criticality Analysis for optimising OPEX cost lifecycle. IFAC-PapersOnLine 2016, 49, 7-12. [CrossRef]

43. Nakajima, S. Introduction to TPM: Total Productive Maintenance; Productivity Press: New York, NY, USA, 1988; p. 129.

44. Paraszczak, J. Understanding and assessment of mining equipment. Min. Technol. 2015, 114, 147-151. [CrossRef]

45. Campbell, J.D.; Jardine, A.K.S. Maintenance Excellence: Optimizing Equipment Life-Cycle Decisions; CRC Press: Boca Raton, FL, USA, 2001.

(C) 2019 by the authors. Licensee MDPI, Basel, Switzerland. This article is an open access article distributed under the terms and conditions of the Creative Commons Attribution (CC BY) license (http://creativecommons.org/licenses/by/4.0/). 